\title{
Intrathoracic extramedullary haematopoiesis complicated by massive haemothorax in alpha-thalassaemia
}

Division of Chest

Medicine

K-A Chu

R-S Lai

$\mathrm{J}-\mathrm{Y} \mathrm{Lu}$

Department of Internal Medicine H-T Chiang

Division of Thoracic Surgery

H-C Chang

Veterans General Hospital-Kaohsiung, Kaohsiung, Taiwan, Republic of China

Faculty of Medicine, National Yang-Ming University, Taiwan, Republic of China R-S Lai

$\mathrm{J}-\mathrm{Y} \mathrm{Lu}$

H-T Chiang

School of Medical Technology, Chung Gung University, Taiwan, Republic of China

C-H Lee

Correspondence to: Dr R-S Lai, Division of Chest Medicine, Veterans General Hospital-Kaohsiung 386, Ta-Chung 1st Road, Kaohsiung, Taiwan.

Received 13 February 1997 Returned to authors 13 May 1997 Revised manuscript received 15 July 1997

Accepted for publication

3 December 1997

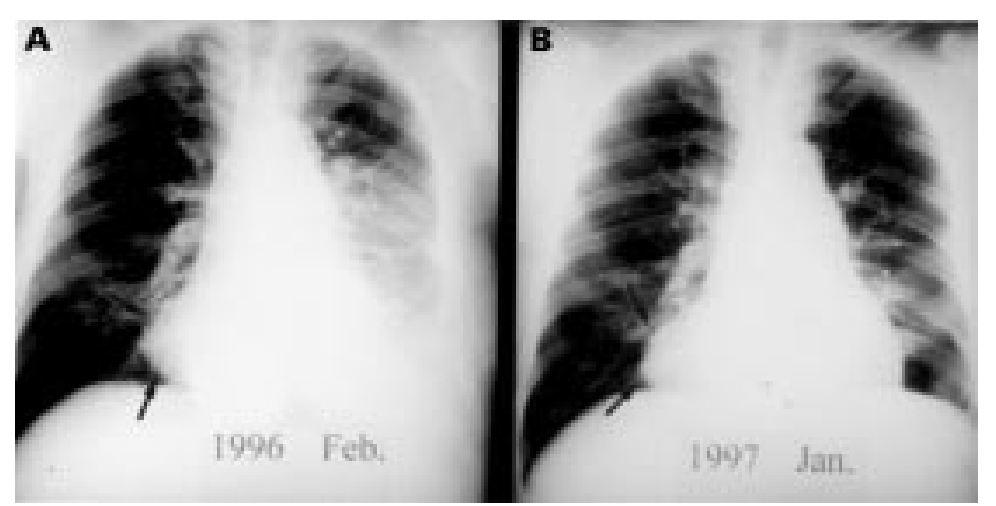

Figure 1 Chest radiograph showing (A) massive left sided pleural effusion and posterior mediastinal masses (arrow) and (B) one year later only the posterior mediastinal mass (arrow) is seen without recurrence of the effusion.

\begin{abstract}
Intrathoracic extramedullary haematopoiesis (EMH) is a rare entity that is usually asymptomatic. A 44 year old man with alpha-thalassaemia is described who developed dyspnoea and massive left sided haemothorax. The haemoglobin disorder was established by Hgb $H$ staining and haemoglobin electrophoretic studies. The DNA analysis revealed it to be a case of double heterozygous terminal codon mutation with the genotype $\alpha \alpha^{\mathrm{CS}} / \alpha \alpha^{\mathrm{T}}$. Computed tomographic scanning and magnetic resonance imaging of the thorax showed multiple paravertebral masses which were found by thoracoscopic biopsy to be extramedullary haematopoiesis. Although no additional sclerosing pleurodesis or low dose radiation therapy was given, the lung expanded well and there has been no recurrence of haemothorax to date.

(Thorax 1999;54:466-468)
\end{abstract}

Keywords: extramedullary haematopoiesis; haemothorax; thalassaemia

Extramedullary haematopoiesis (EMH) occurs as a compensatory phenomenon to several haematological diseases including thalassaemia, myelofibrosis, and hereditary spherocytosis. Intrathoracic EMH is a rare entity which is often located in the lower thoracic paraspinal area and Kuo-An Chu, Ruay-Sheng Lai, Chien-Hong Lee, Jau-Yeong Lu, Huang-Chou Chang,
Hung-Ting Chiang

is usually asymptomatic. We describe the case history of a patient who presented with alphathalassaemia complicated by haemothorax.

\section{Case report}

The patient, a 44 year old man, had a history of alpha-thalassaemia for some years. The disorder was diagnosed by positive haemoglobin $\mathrm{H}$ staining and haemoglobin electrophoretic studies (Hgb H 10.3\%). DNA analysis showed a double heterozygous terminal codon mutation with genotype $\alpha \alpha^{\mathrm{CS}} / \alpha \alpha^{\mathrm{T}}$ (CS $=$ constant spring; $\mathrm{T}=$ terminal codon mutation other than CS). Bone marrow aspiration cytology revealed erythroid hyperplasia. He was admitted in February 1996 with left sided chest pain and dyspnoea for several days. There was no history of trauma. We were unable to obtain a family history of haematological disorder.

Physical examination revealed a blood pressure of $146 / 76 \mathrm{~mm} \mathrm{Hg}$, pulse rate of $95 / \mathrm{min}$, respiratory rate of $19 / \mathrm{min}$, pale conjunctiva, icteric sclera, diminished left sided breathing sounds, and marked hepatosplenomegaly. Initial haematological examination showed a haemoglobin level of $6.8 \mathrm{~g} / \mathrm{dl}$, haematocrit value of $27.1 \%$, mean corpuscular volume (MCV) of $71.9 \mathrm{fl}$, mean corpuscular haemoglobin concentration (MCHC) of $25.1 \mathrm{~g} / \mathrm{dl}$, red blood cell count of $3.7 \times 10^{6} / \mathrm{mm}^{3}$, white blood cell count of $14 \times 10^{3} / \mathrm{mm}^{3}$, and platelet count of $2.7 \times 10^{5} / \mathrm{mm}^{3}$. Serum biochemical analysis gave the following values: iron $140 \mu \mathrm{g} /$ $\mathrm{dl}$, ferritin $374 \mathrm{ng} / \mathrm{ml}$, total iron binding capacity (TIBC) $187 \mu \mathrm{g} / \mathrm{dl}$, and total bilirubin $4.6 \mathrm{mg} / \mathrm{dl}$. Chest radiography showed a massive left sided pleural effusion and posterior mediastinal masses (fig 1). Computed tomographic scanning of the chest revealed multiple lobulated paravertebral masses over the $T$ spine with good contrast enhancement (fig 2). Magnetic resonance imaging of the thorax showed elongated lobulated paraspinal masses with isointensity to muscle on T1-weighted images and hyperintensity on T2-weighted images. Thoracocentesis revealed a bloody effusion with a protein level of $6500 \mathrm{mg} / \mathrm{dl}$, sugar $5 \mathrm{mg} / \mathrm{dl}$, red blood cell count $3.4 \times$ $10^{6} / \mathrm{mm}^{3}$, white blood cell count $2 \times 10^{4} / \mathrm{mm}^{3}$, and negative cytological results. Video-assisted 


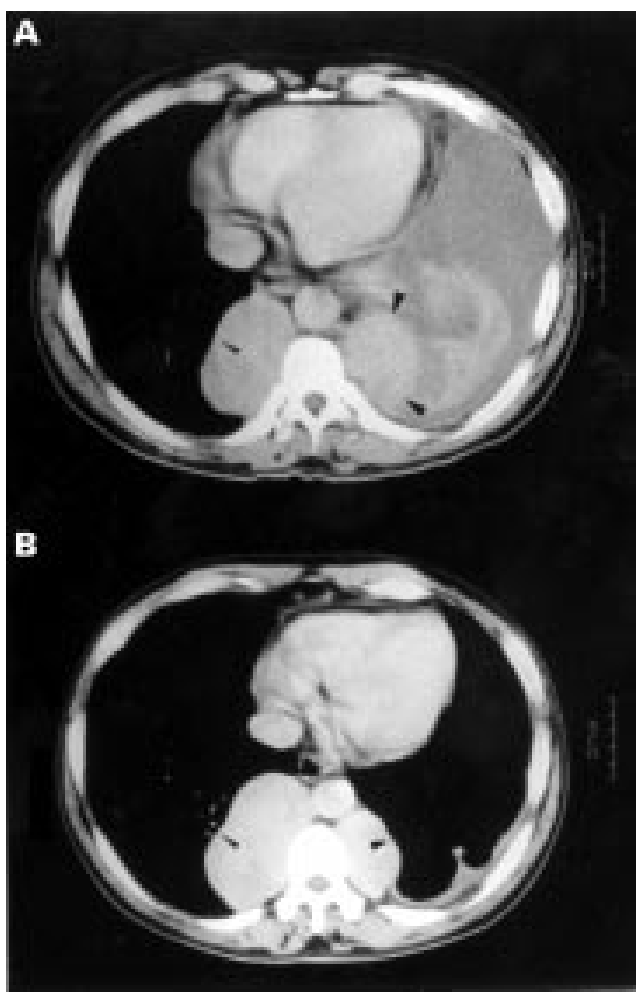

Figure 2 Computed tomographic scan of the chest showing (A) massive left sided pleural effusion and multiple lobulated paravertebral masses with well enhanced contrast (arrowheads) and (B) one year later only multiple lobulated paravertebral masses (arrowhead) were found.

thoracoscopy disclosed several lobulated reddish tumour masses over the lower paravertebral region and a large amount of bloody effusion. The pathological findings of a biopsy specimen of the tumour obtained by thoracoscopy revealed normal haematopoietic tissue with normal maturation process of three lineage cells.

The patient was discharged in fair condition three weeks later without additional preventive sclerosing therapy or low dose radiation therapy. Follow up chest radiography revealed almost complete reabsorption of the left sided haemothorax and there has been no recurrence of bleeding to date.

\section{Discussion}

Alpha-thalassaemia is caused by deletion or mutation of $\alpha$-globin genes. In order of increasing severity they are $\alpha$-thalassaemia- 2 trait $(-\alpha / \alpha \alpha), \alpha$-thalassaemia-1 trait $(-/ \alpha \alpha)$ $(-\alpha /-\alpha), \mathrm{Hb} \mathrm{H}$ disease $(-/-\alpha)$, and $\mathrm{Hb}$ Barts (-/-). Haemoglobin constant spring (HbCS) is a common non-deletional $\alpha$-thalassaemia mutation and is an important cause of $\mathrm{HgH}$-like disease in south-east Asia. ${ }^{1}$ The genotype $\alpha \alpha^{\mathrm{CS}} / \alpha \alpha^{\mathrm{T}}$ established in our patient by polymerase chain reaction is an uncommon genotype of $\mathrm{Hg} \mathrm{H}$ disease. Extramedullary haematopoiesis usually develops as a compensatory response in various anaemias including thalassaemia, sickle cell anaemia, and myelofibrosis. It usually occurs in the blood forming organs outside the bone marrow such as the spleen, liver and lymph nodes, but it is also found more rarely as a mass-like lesion within the thorax. Intrathoracic EMH commonly develops in the posteroinferior mediastinum, but has also been reported in the anterior mediastinum. It is usually asymptomatic and can be found by microscopic examination, ${ }^{2}$ but it may also present as a single or multiple large tumour with occasional symptoms of spinal cord compression ${ }^{3}$ or haemothorax. ${ }^{24-6}$

As far as we are aware, only four patients with intrathoracic EMH complicated with haemothorax have been previously reported in the English literature. Smith et $a l^{4}$ reported a case of thalassaemia intermedia who developed intrathoracic EMH and haemothorax which was treated with local radiation therapy to prevent recurrent bleeding. Muthuswamy and colleagues $^{5}$ described a patient with hereditary spherocytosis who presented with posttraumatic intrathoracic haemorrhage due to intrathoracic EMH. Kupferschmid and colleagues $^{2}$ reported a case of myelofibrosis with intrathoracic EMH. The complicated massive haemothorax did not respond to tetracycline pleurodesis and was ultimately controlled with low dose radiation therapy. Bartlett et $a l^{6}$ described a case of agnogenic myeloid metaplasia with haemothorax. The intrathoracic EMH, confirmed by a technetium-99 bone marrow scan, was treated successfully with low dose irradiation to prevent recurrent haemothorax. In the case presented here, thoracoscopic biopsy and decortication were performed not only for tissue diagnosis of the posterior mediastinal mass but also for better lung expansion.

Various non-invasive diagnostic procedures are advocated to establish the diagnosis of EMH. These include contrast enhanced computed tomography, ${ }^{7}$ magnetic resonance imaging of the thorax, ${ }^{8}$ technetium-99 sulphur colloid radionuclide bone marrow scanning, ${ }^{9}$ cytological study of the pleural fluid, and fine needle aspiration examination which may carry a risk of haemorrhagic complications. Computed tomographic scanning of intrathoracic EMH typically reveals smoothly marginated mass(es) with homogenous soft tissue over the lower paravertebral regions without bony erosion. A radionuclide bone marrow scan may demonstrate activity in the mass. ${ }^{\circ}$

Treatment of intrathoracic EMH is usually unnecessary except in the presence of complications. Because the haematopoietic tissue is highly radiosensitive, low dose radiation has been suggested as an effective method for controlling symptomatic spinal cord compression ${ }^{10}$ and haemothorax. ${ }^{246}$ In our patient, because it was the first episode of haemothorax and there was good expansion of the lung after tube thoracostomy, we did not apply local radiation therapy. To date there has been no evidence of recurrent haemothorax.

In conclusion, based on the characteristic radiographic findings and radionuclide marrow scanning, it is important to recognise the possibility of intrathoracic EMH as a differential diagnosis of non-traumatic haemothorax, especially in patients with bone marrow insufficiency or chronic haemolytic anaemia. Although radiation therapy or sclerosing pleurodesis is suggested for recurrent haemothorax, 
tube thoracostomy with regular follow up is an alternative effective treatment in intrathoracic EMH with massive haemothorax.

1 Schrier SL, Bunyaratvej A, Khuhapinant A, et al. The unusual pathobiology of hemoglobin constant spring red blood cells. Blood 1997;89:1762-9.

2 Kupferschmid JP, Shahian DM, Villanueva AG. Massive hemothorax associated with intrathoracic extramedullary hematopoiesis involving the pleura. Chest 1993;103:974-5.

3 Pile-Spellman J Adelm the Pelramedullary hematopoiesis causing $1981 ; 8: 728-31$.

4 Smith PR, Manjoney DL, Teitcher JB, et al. Massive hemothorax due to intrathoracic extramedullary hematopoiesis in
5 Muthuswamy PP, Shah P, Patel R, et al. Intrathoracic extramedullary hematopoiesis simulating post-traumatic intrathoracic hemorrhage. Am F Med 1989;86:358-60.

6 Bartlett RP, Greipp PR, Tefferi A, et al. Extramedullary hematopoiesis manifesting as a symptomatic pleural effusion. Mayo Clin Proc 1995;70:1161-4.

7 Gumbs RV, Higginbotham-Ford EA, Teal JS, et al. Thoracic extramedullary hematopoiesis in sickle-cell disease. AfR 1987;149:889-93.

8 Savader SJ, Otero RR, Savader BL. MR imaging of intrathoracic extramedullary hematopoiesis. I Comput Assist Tomogr 1988;12:878-80.

9 Bronn LJ, Paquelet JR, Tetalman MR. Intrathoracic extramedullary hematopoiesis: appearance on $99 \mathrm{~m} \mathrm{Tc}$ sulfur colloid marrow scan. AfR 1980;134:1254-5.

10 Papavasiliou C, Sandilos P. Effect of radiotherapy on symptoms due to heterotopic marrow in beta-thalassemia. Lancet $1987 ; \mathrm{i}: 13-4$

\section{LETTERS TO THE EDITOR}

\section{$\mathrm{FEV}_{1}$ and PEF in COPD management}

Chronic obstructive pulmonary disease (COPD) is a common disease usually treated in general practice, especially in the early stages. ${ }^{1}$ The recently published British Thoracic Society guidelines encourage a systematic approach to the management of COPD as is widely used in asthma. ${ }^{2}$ Lung function measurements are regarded as central to the correct implementation of the guidelines. The guidelines are unequivocal in advising the use of forced expiratory volume in one second $\left(\mathrm{FEV}_{1}\right)$ rather than peak expiratory flow (PEF) in the management of COPD: " . . in COPD the relationship between PEF and $\mathrm{FEV}_{1}$ is poor and it is not possible to predict FEV from the PEF or vice versa." This is a key issue for GPs who have to decide now whether or not to purchase a spirometer, and whether they have the organisational capacity to cope with the maintenance, calibration, and interpretation demands of modern spirometers.

We have investigated the literature examining the relationship between $\mathrm{FEV}_{1}$ and PEF and exploring their use in COPD. We have been unable to find substantive evidence to support the statement in the BTS guidelines regarding the superiority of FEV over PEF. The only citation among the 171 references offered in the guidelines to support their position is a paper by Kelly and Gibson. ${ }^{3}$ In fact, Kelly and Gibson state the opposite view and report a very strong correlation between FEV and PEF with an $r$ value of $0.95(\mathrm{p}<0.001)$. A similarly strong relationship between the two parameters has been reported by others. ${ }^{4}$

The close relationship between $\mathrm{FEV}_{1}$ and $\mathrm{PEF}$ is reassuring to us because the arguments put forward by the COPD guidelines seem counter-intuitive to GPs working daily with $\mathrm{PEF}$ in asthma. We recognise the role of spirometry as a whole in the diagnosis of COPD, especially in distinguishing primarily restrictive from obstructive disease. In the continuing management of COPD, however,we suspect that spirometry has little additional value to offer over PEF, but considerable practical disadvantages.
DERMOT NOLAN PATRICK WHITE Department of General Practice and Primary Care, Guy's, King's and St Thomas' Medical School, Weston Education Centre, Bessemer Road, London SE5 9PF, UK

1 McCormick A, Fleming D, Charlton J. Morbidity statistics from general practice: 4th national study 1991-2. London: Office of Population Censuses and Surveys, 1995.

2 British Thoracic Society. Guidelines for the management of chronic obstructive pulmonary disease. Thorax 1997;52 (Suppl 5).

3 Kelly CA, Gibson GJ. Relationship between $\mathrm{FEV}_{1}$ and peak expiratory flow in patients with $\mathrm{FEV}_{1}$ and peak expiratory flow in patients with
chronic obstructive pulmonary disease. Thorax 1988;43:335-6.

4 Lebowitz MD, Knudson RJ, Robertson MS, et al. Significance of intraindividual changes in
and maximal expiratory flow volume and peak expiratory flow measurements. Chest 1982;81: $566-70$

5 Ritchie B. A comparison of forced expiratory volume and peak flow in clinical practice. Lancet 1962;ii:271-3.

AUTHORS' REPLY Drs Nolan and White are concerned that GPs might be persuaded to buy spirometers when peak flow meters might perform just as well. The guidelines list a number of reasons why FEV is preferable to $\mathrm{PEF}$ in managing COPD. They attack one specific aspect but unfortunately misquote their references. The figure they quote from Kelly and Gibson ${ }^{1}$ applies to a previous 61 patients undergoing routine testing (not all with COPD) and not to the 10 subjects with COPD and a positive steroid trial in whom the relative changes in $\mathrm{PEF}$ and $\mathrm{FEV}_{1}$ do not exhibit the same slopes. Liebowitz ${ }^{2}$ studied 10 healthy individuals and none with COPD. The 1962 Lancet article by Ritchie ${ }^{3}$ dates from the infancy of $\mathrm{FEV}_{1}$ and long before COPD was defined as a discrete entity.

The most important and fundamental poin is that PEF cannot differentiate between obstructive and restrictive patterns of abnormal function. If the diagnosis is not made correctly then the GP cannot hope to manage the patient correctly. The implications of a restrictive defect will often necessitate referra to secondary care to assess the cause, whereas most cases of mild to moderate COPD are manageable within primary care.

The $\mathrm{FEV}_{1}$ is a more reproducible measurement so that measurements on a single occasion can be of value whereas, to obtain similar accuracy with $\mathrm{PEF}$, serial measurements are required. By inspecting the $\mathrm{FEV}_{1}$ traces it is possible to know whether a patient has performed the manoeuvre correctly, whereas no such confirmation exists for PEF. Even in asthma, studies of repeated measurements of serial PEF using computerised measurements confirm that up to $50 \%$ of readings may be non-valid. ${ }^{45}$

To understand the relationship between the level of PEF and the level of FEV 1 it is necessary to go - not to epidemiology - but to the physiology underlying the shape of the flow-volume loop in COPD. In the first draft of the guidelines we included a figure illustrating how the $\mathrm{FEV}_{1}$ could be reduced to $33 \%$ of predicted at a time when the PEF remains relatively preserved at $60 \%$ of predicted. The discrepancy arises because of the airway collapsibility present in COPD secondary to the loss of elastic tissue. The PEF is generated by the instantaneous flow of air leaving the trachea in the first 0.1 seconds of expiration, while the FEV, includes air leaving the airways through airways that have collapsed after about 0.2 seconds of expiration (fig 1). In the example shown a patient with severe COPD (lower line) is compared with the predicted normal pattern (upper line). The patient's $\mathrm{FEV}_{1}$ is markedly reduced to $0.81(33 \%)$ while the PEF is relatively preserved at $5.7 \mathrm{l} / \mathrm{s}$ (or $340 \mathrm{l} / \mathrm{min}$ ) which is $80 \%$ predicted. As expiration begins (point "a") there is a rapid increase in expiratory flow until the flow becomes limited by the airway dimensions and peak flow is reached (point "b"). As expiration continues in the healthy subject so flow decreases slowly and progressively until the residual volume is reached when flow ceases (point "c"). In the patient with COPD the initial rapid rise in expiratory flow is similar but, as the intrathoracic pressure increases, that pressure is transmitted to the segmental and other largeairways which have lost the elastic attachments. The airways therefore "collapse" and obstruct the passage of air through those airways. This results in the rapid reduction in flow after the peak has been attained (point "d"). Flow in the remainder of the expiration remains limited. The effect of the expiratory airway collapsibility is shown by the time points marked. The subject with COPD reaches peak flow at about $100 \mathrm{~ms}$ and has reached the point of expiratory collapse (point "d") within $0.25 \mathrm{~s}$. Thus, for the remaining $0.75 \mathrm{~s}$ contribution to the FEV, measurement, flow is at the very low level shown. As the airway collapsibility varies between COPD patients, the relationship between PEF and $\mathrm{FEV}_{1}$ will also vary. Because PEF can be misleadingly optimistic it is severely limited as a diagnostic tool. This figure was edited out of the guidelines, possibly on the mistaken grounds that it was too obvious a point. 


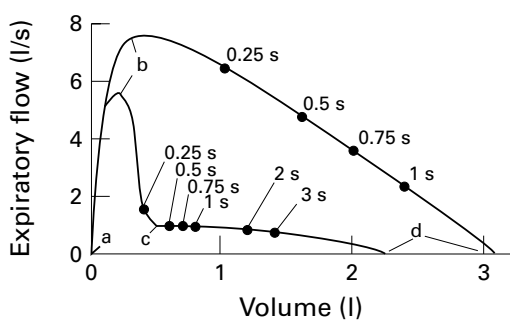

Figure 1 Flow-volume trace with time points in health and COPD.

Last $\mathrm{FEV}_{1}$ is a measure both of current severity of disease (which dictates likely treatments to be considered) and also of prognosis. Indeed, $\mathrm{FEV}_{1}$ has a prognostic value even beyond COPD as can been seen from the Renfrewshire 21 year prospective study where $\mathrm{FEV}_{1}$ had greater prognostic value than many other frequently measured variables including serum cholesterol.

The $\mathrm{FEV}_{1}$ is here to stay.

M G PEARSON

Aintree Chest Centre, University Hospital Aintree, Longmoor Lane, Liverpool L9 7AL, UK

1 Kelly CA, Gibson GJ. Relation between FEV and peak expiratory flow in patients with chronic airflow obstruction. Thorax 1988;43:335-6.

2 Liebowitz MD, Knudsen RJ, Robertson G, et al. Significance of intraindividual changes in maximum expiratory flow volume and peak expiratory flow measurements. Chest $1982 ; 81$. 566-70.

3 Ritchie B. A comparison of forced expiratory volume and peak flow in clinical practice. Lancet 1962;ii:271-3.

4 Malo J-L, Trudeau C, Glazzo H, et al. Do subjects investigated for occupational asthma through serial peak flow measurements falsify their results? F Allergy Clin Immunol 1995;96: their resul $601-7$.

5 Verschelden P, Cartier A, L'Archeveque J, et al. Compliance with and accuracy of daily self assessment of peak expiratory flow (PEF) in asthmatic subjects over a 3 month period. Eu Respir 7 1996;9:880-5

6 Hole DJ, Watt GCM, Davey Smith G, et al. Impaired lung function and mortality in men and women: findings from the Renfrew and Paisley prospective population study. $B M \mathcal{F}$ 1996;313:711-5.

\section{Health effects of passive smoking}

Cook and Strachan are to be congratulated on their series of meta-analyses on the health effects of passive smoking. However, in their analysis of parental smoking and spirometric indices they gave as the main reason for excluding 19 out of 42 studies that met their primary criteria that they "provide some data, but insufficient to be included in the quantitative overview". ${ }^{1}$ In the case of our own study ${ }^{2}$ they concluded that they were unable to transform our results to the desired effect measure. They used the "difference in outcome measure between the exposed and non-exposed children expressed as a percentage of the level in the non-exposed group" and reported that they were unable to do this with our results as we "reported differences in standard deviation scores with no baseline data".

The standard deviation scores were calculated using the mean and standard deviation of the ratio of actual to lung function predicted for height, age and sex. ${ }^{3}$ Hence, the approximate percentage difference can be calculated by multiplying by the appropriate published standard deviation. Using an esti- mate of 15.6 cigarettes per day for the average amount smoked by parents at home, calculated from the same data for white English children in $1988,{ }^{23}$ the effect of parental smoking on forced expiratory volume in one second (FEV) was $-0.37 \%$ (SE $0.51 \%$ ) for boys and $-0.18 \%$ (SE $0.77 \%$ ) for girls. The wide confidence intervals on our estimates encompass the greater negative estimates of Cook et $a l,{ }^{1}$ but inclusion of our results would have decreased their negative estimates for all four lung function parameters.

The approximation in assuming $\mathrm{FEV}_{1}$ percent predicted to be 100 for the unexposed group is no greater an assumption than combining studies using different definitions of parental smoking and different measures of mid expiratory flow. We invite Cook et al to update their estimates accordingly.

SUSAN CHINN ROBERTO J RONA

Department of Public Health Sciences, King's College London, London SE1 3QD, UK

1 Cook DG, Strachan DP, Carey IM. Health effects of passive smoking. 9. Parental smoking and spirometric indices in children. Thorax and spirometric

2 Rona RJ, Chinn S. Lung function, respiratory illness and passive smoking in British primary illness and passive smoking in British
school children. Thorax 1993;48:21-5.

3 Chinn S, Rona RJ. Height and age adjustment for cross-sectional studies of pulmonary function in children aged 6 to 11 years. Thorax 1992;47:707-14.

AUTHORS' REPLY The omission of the study by Rona and Chinn ${ }^{1}$ from our meta-analyses ${ }^{2}$ is not an indictment of their study, but simply a reflection of the way the data were presented. It arose because the standard deviation necessary to transform the estimates in their paper to percentage deficits was not provided in that paper but published elsewhere. ${ }^{3}$ This is unlikely to have occurred in any of the other studies excluded. Updating our estimates to include their study serves to emphasise the robustness of our estimates to exclusion of individual studies. The fixed effects estimate for percentage reduction in $\mathrm{FEV}_{1}$ amongst children in smoking households moved from $-0.9 \%(95 \%$ CI -1.2 to -0.7$)$ to $-0.9 \%$ (95\% CI -1.1 to -0.7$)$ and the random effects estimate from $-1.4 \%(95 \% \mathrm{CI}-1.9$ to $-1.0)$ to $-1.3 \%(95 \% \mathrm{CI}-1.8$ to -0.9$)$.

DEREK G COOK DAVID P STRACHAN IAIN M CAREY

Department of Public Health Sciences, St George's Hospital Medical School, Cranmer Terrace, London SW17 ORE, UK

1 Rona RJ, Chinn S. Lung function, respiratory illness, and passive smoking in British primary illness, and passive smoking in British
school children. Thorax 1993;48:21-5.

2 Cook DG, Strachan DP, Carey IM. Health effects of passive smoking. 9. Parental smoking and spirometric indices in children. Thorax 1998;53:884-93

3 Chinn S, Rona RJ. Height and age adjustment for cross-sectional studies of pulmonary function in children aged 6-11 years. Thorax 1992; 47:707-14.

\section{Investigation and management of persistent dry cough}

McGarvey et $a l^{1}$ suggest that full investigation of patients with persistent cough improves treatment.

I reviewed 100 such patients seen consecutively. All had normal chest radiographs, two were current smokers, and their mean cough
Table 1 Final diagnosis

\begin{tabular}{lrll}
\hline Diagnosis & & $\begin{array}{l}\text { Mean age } \\
\text { (range) }\end{array}$ & $M / F$ \\
\hline Rhinitis & 24 & $46(7-75)$ & $8 / 16$ \\
Reflux & 19 & $53(40-69)$ & $7 / 12$ \\
Post viral & 11 & $38(9-67)$ & $4 / 7$ \\
Reflux + rhinitis & 6 & $58(44-64)$ & $4 / 1$ \\
Whooping cough & 5 & $37(14-64)$ & $4 / 1$ \\
ACE inhibitor (ACE I) & 4 & $62(49-79)$ & $2 / 8$ \\
ACE I + rhinitis + reflux & 1 & & \\
ACE I + rhinitis & 2 & & \\
ACE I + reflux & 3 & & \\
Asthma & 5 & $48(30-68)$ & $4 / 2$ \\
Asthma + rhinitis & 1 & & \\
Interstitial lung disease & & & $1 / 0$ \\
$\quad$ (ILD) & 1 & 78 & \\
Chronic bronchitis & 2 & $77(72-81)$ & $0 / 2$ \\
No diagnosis & 2 & $58(44-71)$ & $0 / 2$ \\
\hline
\end{tabular}

duration was 18.8 months (range one month to 20 years). Initial treatment was given on the basis of history and routine clinical examination with investigations reserved for patients not responding after one month. Thirty four patients failed to return after their initial appointment. Twenty were contacted and all reported complete resolution of their symptoms. Clinical diagnoses in the 14 others were similar and they probably defaulted because of improvement, but have been excluded from analysis. Investigations performed included radiology of the sinuses in $8 \%$, bronchial provocation testing in $16 \%$, and investigation for gastro-oesophageal reflux in $19 \%$. The final diagnoses (table 1) were based on successful response to treatment. Asthma was uncommon ( $7 \%$ ) but, as there were few treatment failures, it seems unlikely that asthma was missed. The awareness of asthma by GPs is high in Australia and most had probably been treated by their GPs. Clinical outcomes were excellent with 79 patients $(92 \%)$ reporting complete or almost complete resolution of cough in a mean of two months.

These results suggest that good outcomes can be achieved in most patients without routine investigation. The poor positive predictive values of symptoms quoted by McGarvey et al reflect poor choice of historical features. These authors confirm that any cause of chronic cough increases the sensitivity of the cough reflex, and the finding that cough precipitated by non-specific stimuli is poorly predictive of asthma is unsurprising. Likewise, most patients with reflux associated cough do not have heartburn. ${ }^{2}$

Diagnostic protocols advocated by hospital based researchers may be inappropriate for other settings. Such protocols should be subjected to randomised control trial against less interventionist approaches as would be required of a new drug treatment.

GRAHAM SIMPSON

Clinical Associate Professor, University of Queensland, Queensland, Australia

1 McGarvey LPA, Heaney LG, Lawson JT, et al. Evaluation and outcome of patients with chronic non-productive cough using a comprehensive diagnostic protocol. Thorax 1998;53:738-43

2 Ing AJ, Ngu MC, Breslin ABX. Chronic persistent cough and gastro-oesophageal reflux. Tho$\operatorname{rax} 1991 ; 46: 479-83$.

AUTHORS' REPLY We welcome Dr Simpson's interesting comments. He describes a group of patients which appears to be rather different from the patients reported in our study. ${ }^{1}$ Firstly, our patient group had been troubled with cough for a longer period of time (mean cough duration 67 months (range 2-240) 
compared with 18.8 months (range 1-240)) Secondly, application to his study of our exclusion criteria-that is, smokers, an abnormal chest radiograph, any preceding viral infections, and patients taking angiotensin converting enzyme inhibitors-would mean that 29 of the 86 patients (33\%) he reviewed would not have been included in our study. Dr Simpson relies heavily on patient history in the evaluation of his patients. In our discussion we highlight the limitations of historical features, given the existence of both silent "reflux" and postnasal drip. We do not accept that the poor positive predictive values reflect a bad choice of historical features and believe there are no accurate discriminatory historical features that can be reliably applied to cough patients in general. This is supported by a study which specifically examined features in the clinical history and found that these were unlikely to be useful in diagnosing the cause of cough. ${ }^{2}$

While we agree that a randomised controlled trial may be one way to address the issue of how best to evaluate patients with cough, we suspect that Dr Simpson is describing a very different patient population from those referred to our cough clinic and that a less interventionist approach may not therefore be appropriate. In the meantime we feel a comprehensive protocol which is consisten with the approach of the recent Consensus Panel Report of the American College of Chest Physicians ${ }^{3}$ continues to represent the optimum way to evaluate patients referred with chronic cough.

$$
\begin{array}{r}
\text { LORCAN P A MCGARVEY } \\
\text { LIAM G HEANEY } \\
\text { JOSEPH MACMAHON } \\
\text { Department of Respiratory Medicine, } \\
\text { Belfast City Hospital, Belfast BT9 } 7 A B, \text { UK }
\end{array}
$$

1 McGarvey LPA, Heaney LG, Lawson JT, et al. Evaluation and outcome of patients with chronic non-productive cough using a comprehensive diagnostic protocol. Thorax 1998;53:738-43.

2 Mello CJ, Irwin RS, Curley FJ. The predictive values of the character, timing and complications of chronic cough in diagnosing its cause. Arch Intern Med 1993:119:977-83.

3 Irwin RS, Boulet LP, Cloutier MM, et al. Managing cough as a defense mechanism and as a symptom: a consensus panel report of the American College of Chest Physicians. Chest 1998;114:133-81S.

\section{Targeting DNase in cystic fibrosis}

Recombinant human DNase is an expensive mucolytic which does not benefit all patients with cystic fibrosis. Company sponsored trials in unselected cystic fibrosis patients have documented wide variability in spirometric responses to the drug, but the data are presented in a way which prevents the clinician from assessing which patients are likely to benefit.

We therefore read with interest the editorial by Dr Innes regarding the assessment of response to DNase in cystic fibrosis. ${ }^{1}$ However, whilst we agree that it is necessary to target DNase, we have reservations regarding the use of "n-of-1 trials" for this therapy. Dr Innes states that this approach has been used in Scotland and quotes a study unpublished at the time of writing in support of it. However, this study has already been heavily criticised since many patients refused to take part and others did not complete the trial periods. $^{2}$ Furthermore, such studies are inherently time consuming and resource intensive.

We have adopted a different approach to ensure that DNase is prescribed in a rational fashion. Before it became available on the NHS we met with local purchasers to define selection criteria and a trial protocol. Following selection, those who have an improvement in forced expiratory volume in one second $\left(\mathrm{FEV}_{1}\right)$ of $\geqslant 10 \%$ after a trial of DNase are defined as "responders" and remain on the drug. A review at two years has shown that, whilst responders maintain their improvement, non-responders are not disadvantaged. $^{3}$ Thus, using this protocol we have been able to target DNase to those patients who obtain maximum benefit. This model has now been widely accepted by purchasers for adult and paediatric cystic fibrosis services in North Wales and the Northwest of England and, as such, we have no problems in obtaining funding for this very expensive product.

We suggest that Dr Innes and his colleagues abandon their "n-of-1 trials" and adopt our protocol for the use of DNase.

MARTIN J LEDSON MARTIN J WALSHAW Regional Adult Cystic Fibrosis Unit, The Cardiothoracic Centre, Thomas Drive, Liverpool L14 3PE, UK

1 Innes JA. DNase in cystic fibrosis: the challenge and maximising benefit. Thorax 1998;53:1003-4.

2 Beard K, Forrester E, Lee A, et al. Systems and strategies for managing the drugs budget in Glasgow. BMF 1998;317:1378-81.

3 Ledson MJ, Wahbi Z, Convery RP, et al. Targeting of dornase alpha therapy in adult cystic fibrosis. F R Soc Med 1998;91:360-4.

AUTHOR'S REPLY We would urge Drs Ledson and Walshaw, before suggesting we abandon the Scottish n-of-1 DNase assessment protocol, to read it! ${ }^{1}$ The protocol has not been "heavily criticised" as they claim since the article they quote ${ }^{2}$ was also written without knowledge of the results (only recently published). In our experience it is very unusual for patients to refuse to undergo our assessment process.

Where we do agree is in the need to test the DNase response in individual patients. However, we disagree on how this should be done. Ledson and Walshaw advocate an unblinded, open label, two week trial of DNase using an increase in $\mathrm{FEV}$ of $>10 \%$ as the only end point. We contend that this is less than ideal because (a) double blinding and placebo control periods are needed to obviate bias, given the high expectations generated in patients and carers by new treatments for cystic fibrosis; (b) using the single end point of increased $\mathrm{FEV}_{1}$ may be less reliable than combining this with other measures including exercise capacity, oxygen saturation and symptom scores; (c) a criterion of a $>10 \%$ increase in $\mathrm{FEV}$, is inherently unreliable since day-to-day variability in $\mathrm{FEV}_{1}$ is around $160 \mathrm{ml}(95 \% \mathrm{CI})$ regardless of the magnitude of the $\mathrm{FEV}_{1}{ }^{3}$ so it is easy for patients with a low $\mathrm{FEV}_{1}$ to achieve an increase of $>10 \%$ by chance. Indeed, Ledson et al in the description of their own protocol ${ }^{4}$ quote the day-today variability of $\mathrm{FEV}_{1}$ in cystic fibrosis as "up to $13 \%$ ", so clearly some $10 \%$ increases will be spurious. We agree that DNase can and should be targeted to maximise benefit, but feel that this targeting should be made as objective as possible. This may be laborious for doctors, but it is not nearly as laborious for patients as consigning a non-responder to long term daily nebulised therapy on unreliable evidence.

\section{J ALASTAIR INNES Scottish Adult Cystic Fibrosis Service, Western General Hospital, Crewe Road, Edinburgh EH4 2XU, UK}

1 Böllert FGE, Paton JY, Marshall TG, et al. Recombinant DNase in cystic fibrosis: a protoRecombinant DNase in cystic fibrosis: a prototrials. Eur Respir f 1999;13:107-13.

2 Beard K, Forrester E, Lee A, et al. Systems and strategies for managing the drugs budget in Glasgow. BMF 1998;317:1378-81

3 Tweeddale PM, Alexander F, McHardy GJR. Short term variability in $\mathrm{FEV}_{1}$ and bronchodilator responsiveness in patients with obstructive ventilatory defects. Thorax 1987;42:487-

4 Ledson MJ, Wahbi Z, Convery RP, et al. Targeting of dornase alpha therapy in adult cystic fibrosis. F R Soc Med 1998;91:360-4.

\section{NOTICES}

\section{Cochrane Airways Group}

An international stymposium on "The Basis for Clinical Excellence in the Treatment of Chronic Lung Diseases" organised by the Cochrane Airways Group will be beld on 10-11 November 1999 at the Royal Society of Medicine, London. For further information contact Alison Rowley, Symposium Administration Office, Cochrane Airways Group, Battersea Studios, Thackeray Road, London SW8 3TW, UK. Telephone +44 (0)1799 542993. Fax +44 (0)1799 541026. email: greene_room@msn.com

\section{World Association of Sarcoidosis and Other Granulomatous Disorders}

The 17th World Congress on Sarcoidosis and Other Granulomatous Disorders (WASOG) will be held in Fumamoto, Japan on 8-13 November 1999. Further details may be obtained from Professor Masayuki Ando, Kumamoto University School of Medicine, 1-1-1 Honjo, Kumamoto 860, Japan. Telephone +96-373-5150. Fax +96-371-0582.

\section{CORRECTION}

In the "Smoking Cessation Guidelines and their Cost Effectiveness" which was published as a supplement to the December issue of Thorax (December 1998; 54 (Suppl 5)), the name of one reviewer was inadvertently omitted from the list of reviewers on page $S 1$ of Part 1:

Gay Sutherland, Clinical Psychologist, National Addiction Centre, Institute of Psychiatry, University of London, London, UK. 